\title{
Back to the future of RNA structure
}

\section{JULI FEIGON}

Department of Chemistry and Biochemistry, University of California, Los Angeles, Los Angeles, California 90095-1569, USA

The first issue of RNA appeared 20 years ago in March, 1995 with Tim Nilsen as Editor, with a cover that featured a ribbon diagram of a model of the self-splicing Group I intron based on phylogenetic analysis by Francois Michel and Eric Westhof. At that time, there were fewer than 15 RNA structures, including RNA-DNA and RNA-protein complexes, in the Brookhaven Data Base (now known as the Protein Data Base). By the end of 1996, there were over 40; this "explosive" growth in RNA structural studies led to the first ever meeting on RNA Structure, organized by Harry Noller and others and held at UC Santa Cruz in June, 1997. Olke Uhlenbeck was recruited to write a review of that meeting, and he in turn recruited Art Pardi and myself to help him (Uhlenbeck, Pardi, and Feigon, Cell, 1997). Looking back, it was an exciting time! The review of the meeting provides a window into that time frame. The structure of the Tetrahymena group I intron P4/P6 domain had just been published (Cate et al Doudna, Nature, 1996), which, at $160 \mathrm{nt}$, was the largest RNA structure solved since the $96 \mathrm{nt}$ phenylalanine tRNA structures reported 22 years earlier independently by the Aaron Klug and Alex Rich labs. (The P4/P6 structure became the second cover picture of $R N A$, volumes 3-6 from 1997-2000.) This structure verified many structural predictions based on biochemical data while also providing atomic details of helical structure, folding, packing, and interactions, many of which could not have been predicted. About 33 other RNA (only) solution NMR (23) and X-ray crystal (10) structures were presented in talks and posters at the meeting (about half of which were not yet published). These comprised domains of rRNA (the largest being $62 \mathrm{nt}$ of $5 \mathrm{~S}$ rRNA), viral RNAs, ribozymes, mRNA, and snRNAs; the hammerhead ribozyme; in vitro selected RNA aptamers; and RNA duplexes. On a personal note, our first structure of an RNA aptamer, the ATP aptamer bound to AMP, was published in RNA (Dieckman et al. 1996), with an accompanying perspective on NMR structures of aptamers by Tom Cech and Alexander Szewczak. Each of these RNA structures revealed details of new and/or common RNA structure motifs, including U-turns, A-platforms, reverse sugars, inter-strand purine stacks, base zippers, base triples, base quadruples, and pseu-

\footnotetext{
Corresponding author: feigon@mbi.ucla.edu

Article and publication date are at http://www.rnajournal.org/cgi/doi/10. 1261/rna.050716.115. Freely available online through the RNA Open Access option.
}

doknots, irregular helices with non-Watson-Crick base pairs, bulges, internal loops and tetraloops, along with details of the long range tetraloop receptor-tetraloop interactions. Major themes of the 1997 meeting, in addition to structures of small RNA motifs, were roles of monovalent and divalent cations on folding, stability, and catalysis including the hammerhead ribozyme, biochemical and computational methods for determining RNA folding and dynamics, structures of RNAprotein complexes, and predictions of large RNA structures (i.e., group II intron, RNAse P RNA, rRNA) based on phylogenetic, thermodynamic, cross-linking, chemical probing, and other data. Of the RNA-protein complexes were structures of tRNA bound to tRNA synthetases and to elongation facture $T_{u}$, but only a few examples of other RNA-protein complexes. These included crystal structures of a complex of virus MS2 coat protein bound to a hairpin RNA, the first dsRBD-RNA complex by Steve Schultze, U2A-U2B"RRMRNA ternary complex by Kiyoshi Nagai, and the first solution NMR structure of an RNA-protein complex, the U1A Nterminal RRM with U1A mRNA fragment from Gabriele Varani's lab presented by his former graduate student and my then current postdoc Frederic Allain. Nearly 20 years ago the ribosome was considered "the ultimate example of a big problem in RNA structural biology." Pictures of ribosome crystals were shown by Harry Noller and Tom Steitz, but solving X-ray structures of the ribosome still appeared to be a monumental challenge.

Despite our predictions to the contrary, the first highresolution structures of the ribosome were published before the millennium (and the 16S rRNA structure in the 70S ribosome was on the cover of RNA for volumes 7 and 8 , years 2001-2002). Today we have many structures of ribosomal small and large subunits, complete ribosomes, and ribosomes with different subunits, at various stages of translation, and with inhibitors. While still a challenge, many crystal structures of complete ribozymes as well as riboswitches have been determined. A current search for RNA in the PDB yielded 1068 structure hits, of which 248 were published in RNA (and since 2003 each issue of RNA has featured a different structure on the cover).

(C) 2015 Feigon This article, published in RNA, is available under a Creative Commons License (Attribution-NonCommercial 4.0 International), as described at http://creativecommons.org/licenses/by-nc/4.0/. 
When the RNA journal began and the first RNA Structure meeting was held, it appeared evident that RNA structural biology had reached a new frontier. Yet as that frontier has receded, new frontiers have come into view. While the major themes of the first RNA Structure meeting would be familiar to readers of RNA in a meeting held in 2015, the field of RNA molecular and structural biology has expanded enormously. Twenty years ago the known important RNAs were tRNA, mRNA, rRNA, snRNAs, ribozymes, introns, viral RNAs (pseudoknots), and in vitro selected aptamers. Small nucleolar RNAs were just starting to be characterized and 7SK RNA was an exception to the rule. Even the most RNA-centric "RNA world" scientist could not have predicted the prevalence and variety of biologically important RNAs and RNPs and their myriad functions that have now been discovered. A recent elegant review by Tom Cech and Joan Steitz (Cell, 2014) lists 54 classes of RNA, including many with vast numbers such as riboswitches, lncRNAs, microRNAs, snoRNAs and scaRNAs. Many of these non-coding RNAs function as a component of RNPs, and many of the RNPs are dynamic assemblies with proteins that come on and off a core RNP for regulation of function. Many RNAs also assume different structures for different functions, e.g., viral RNAs as well as riboswitches. The growing numbers of functional noncoding RNA and RNPs present new targets as well as new challenges for RNA structural biology.

Fortunately, the last few years have presented structural biologists with new and improved tools for structural biology. Once crystals are obtained, data collection at synchrotrons can be fast and efficient. New NMR methods for RNA structure determination, for investigating RNA dynamics over a wide range of time scales, and for detecting small populations (invisible states) of RNA conformations have been developed, and NMR is also one of the best tools for detecting weak interactions. Small angle X-ray scattering (SAXS) has emerged as a useful tool to determine overall shapes of RNAs and RNPs, and is particularly useful when used in combination with high-resolution structures of domains. Fluorescence resonance energy transfer (FRET) and especially single molecule FRET (smFRET) have been used to decipher conformational changes in riboswitches, the ribosome, telomerase, and more. Negative stain and cryolectron microscopy has been and will continue to be tremendously useful for studying RNA assemblies even when only lower resolution EM maps are obtained, as subunits can be localized by affinity labeling and the maps can be fit with higher resolution crystal and NMR structures of domains. This was the case for the EM structure of Tetrahymena telomerase, a collaboration between the laboratories of Kathy Collins, Hong Zhou, and myself (Jiang et al., Zhou, Collins, Feigon, Nature, 2013). But perhaps nothing is more significant than the amazing and ongoing progress in cryoEM single particle analysis over the past couple of years (Bai, McMullan, Scheres, TIBS, 2015). The recent development of directelectron detectors and improved image processing have together led to determination of EM structures at resolutions better than $3.5 \AA$. Notable among these for the RNA field are several structures of ribosomes including the recently reported structure of the human mitochondrial ribosome large subunit. Some major advantages of cryoEM are the very small amounts of sample needed (as little as $0.1 \mathrm{mg}$ ), no requirement for crystallization (for X-ray structures), and in favorable cases the ability to sort out sample impurities and structural heterogeneity during image classification. Although still a considerable challenge, it is also clear that near atomic resolution EM structures are not necessarily limited to large assemblies like the ribosome. A very recent $2.9 \AA$ EM structure of the $440 \mathrm{kD}$ anthrax pore assembly provides an example. Applications of cryoEM to RNA and RNPs other than the ribosome using the new hardware and software are only just beginning, and will clearly bring many exciting new results in the years to come. There are a number of challenges unique to RNA that will need to be overcome, including RNA inter-domain flexibility. A hybrid structural biology approach, incorporating data from NMR, X-ray crystallography, and low and high resolution EM will provide a path to determine not only structures but also dynamics of RNA and RNA assemblies. Coupled with biochemistry these studies should provide new information on RNA and RNP catalytic mechanisms, interactions, and assembly. It is clear that we are entering a new frontier of RNA structural biology. It's (still) an exciting time!

While much has changed in the last 20 years in the RNA world, one constant has been Tim Nilsen as Editor of $R N A$. I would like to take this opportunity to thank him for his profound knowledge, insights and influence on the RNA field, which have benefited RNA scientists both young and old. 

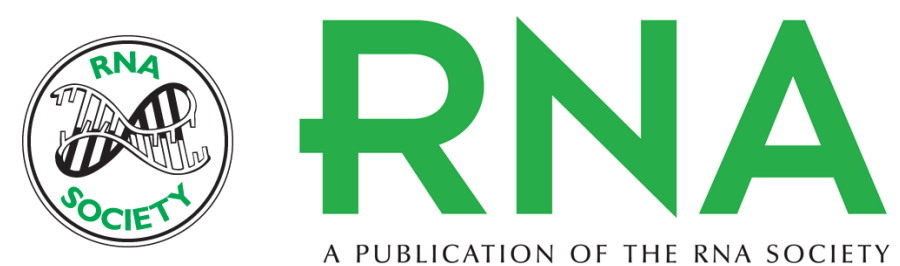

A PUBLICATION OF THE RNA SOCIETY

\section{Back to the future of RNA structure}

Juli Feigon

RNA 2015 21: 611-612

Open Access Freely available online through the RNA Open Access option.

Creative This article, published in $R N A$, is available under a Creative Commons License Commons (Attribution-NonCommercial 4.0 International), as described at License http://creativecommons.org/licenses/by-nc/4.0/.

Email Alerting Receive free email alerts when new articles cite this article - sign up in the box at the Service top right corner of the article or click here.

To subscribe to RNA go to:

http://rnajournal.cshlp.org/subscriptions

(C) 2015 Feigon; Published by Cold Spring Harbor Laboratory Press for the RNA Society 